\title{
Análise da Proposta do Ministério Público para a mediação de conflitos nas escolas: concepções de gestão democrática e diálogo ${ }^{1}$
}

Analysis of the Public Prosecution Proposal for the mediation of conflicts in schools: conceptions of democratic management and dialogue

\begin{abstract}
Alessandro Gomes
Mestre em Educação, pela Universidade do Oeste Paulista. Coordenador de Negócios Educacionais no Serviço Nacional de Aprendizagem Comercial, Marília, SP - Brasil. alessandro.gomes@sp.senac.br

Marcos Vinicius Francisco

Doutor em Educação, pela Universidade Estadual Paulista, campus de Presidente Prudente. Docente do Programa de Pós-Graduação em Educação da Universidade do Oeste Paulista, Presidente Prudente, SP - Brasil. Docente do curso de Educação Física da Universidade Estadual de Maringá, Ivaiporã, PR - Brasil. marcos_educa01@yahoo.com.br
\end{abstract}

Resumo: No presente artigo assumiu-se como objetivo analisar a concepção de gestão democrática e de diálogo presentes na proposta do Ministério Público para a mediação de conflitos nas escolas brasileiras. A pesquisa é de natureza qualitativa, sendo que se recorreu à análise documental como procedimento metodológico. As análises foram estabelecidas a partir do documento Diálogos e Mediação de Conflitos nas Escolas: Guia Prático para Educadores, promovido pelo Conselho Nacional do Ministério Público, órgão externo à escola. Os principais resultados apontaram algumas contradições no Guia, o diálogo proposto não coaduna para a efetivação de uma gestão escolar democrática. Quando os professores e a escola recebem um documento pronto, a fim de se atuar diante das situações promotoras de violência, perdem, automaticamente, suas capacidades para a autonomia, outro princípio básico para a efetivação da gestão democrática.

Palavras-chave: Gestão Escolar Democrática. Diálogo. Mediação de Conflitos nas Escolas.

\begin{abstract}
In this paper, the objective was to analyze the conception of democratic management and dialogue present in the Proposal of the Public Prosecutor for the mediation of conflicts in Brazilian schools. The research is qualitative in nature, and documentary analysis was used as a methodological procedure. The analyzes were established from the document Dialogues and Conflict Mediation in Schools: Practical Guide for Educators, promoted by the National Council of the Public Prosecution, a body outside the school. The main results pointed to some contradictions in the Guide, the proposed dialogue isn't suitable for the implementation of a democratic school management. When teachers and the school receive a document ready, in order to act in situations that promote violence, its capabilities for autonomy, another basic principle for the implementation of democratic management.
\end{abstract}

Keywords: Democratic School Management. Dialogue. Conflict Mediation in Schools.

\section{Abrindo a roda de conversa}

Nesta investigação, defende-se a tese de que a violência praticada no contexto escolar é resultante da ausência do diálogo, o que concerne com perspectivas não democráticas de gestão escolar. A análise será produzida a partir do documento Diálogos e Mediação de Conflitos nas Escolas: Guia 


\section{Dialogia}

Prático para Educadores, como uma forma de compreender aspectos da campanha Conte até 10 nas escolas. Trata-se de um documento de iniciativa do Ministério Público, originado no ano de 2014, por meio do Conselho Nacional de Justiça e de Segurança Pública. Tal documento foi proposto sobre a prerrogativa de que era preciso pensar ações por conta dos alarmantes índices de violência e vitimização dos alunos do Ensino Médio das escolas brasileiras (BRASIL, 2014).

O diálogo, um dos focos deste artigo, traz consigo o caráter problematizador, busca embasamento no conhecimento científico, diante de suas diferentes manifestações: filosófica, histórica e artística. Entende-se por diálogo, também, conversas agregadoras, que valorizam os sujeitos envolvidos, diferentemente daquilo que se apregoa, por exemplo, como discurso competente ${ }^{2}$.

Por definição etimológica, diálogo, é uma palavra que tem origem no latim dialogus, cujos significados se traduzem no ato de conversação entre duas pessoas; por extensão a conversação entre duas ou mais partes, geralmente com vistas a um acordo. Já as raízes gregas "dia" e "logos", juntas apontam que diálogo denota "por meio do significado" (GERARD; TEURFS, 2010).

Ao pensar sobre o diálogo, Paulo Freire definiu essa prática como sendo o "encontro dos homens, mediatizados pelo mundo, para pronunciá-lo, não se esgotando, portanto, na relação eu-tu" (FREIRE, 2005, p. 91). Freire ainda acrescentou que "o diálogo se impõe [...] o caminho pelo qual os homens encontram seu significado enquanto homens" (FREIRE, 2005, p. 91).

Pensando sobre os princípios e fins da escola e da educação, Paro (2004) também se encarrega de enfatizar a necessidade de o diálogo estar presente como forma de proporcionar uma série de conquistas. A educação só pode ocorrer por intermédio de um "processo pedagógico, necessariamente dialógico e não-dominador, que garanta a condição de imprescindibilidade para a realização histórico-humana" (PARO, 2004, p. 108). Tais pressupostos coadunam com a defesa de uma escola movida pela gestão democrática (PARO, 2004).

Nesse sentido, entender, como se deu o processo de transição do regime ditatorial para o regime democrático na política do país, favorece a compreensão de suas influências na educação e na escola dos dias atuais. As ações da ditadura civil-militar no Brasil não se limitaram às leis, mas transcenderam aos limites das relações interpessoais dentro do contexto educacional (CUNHA, 2014). Ao estabelecer um modelo educacional fundamentado em decisões unilaterais, o diálogo deixou de existir, as vozes que deveriam ser ouvidas passaram a se calar ou serem caladas.

A construção da democracia brasileira se solidificou com a Constituição Federal de 1988, caracterizada pela participação popular em sua reformulação e, também, em comparação com as constituições anteriores, diferenciando-se por conta de reunir o mais longo capítulo destinado à educação (BRASIL, 1988). Em seu bojo, assume-se que a educação é um direito público e subjetivo de 


\section{Dialogia}

todo cidadão brasileiro, reforçando o princípio da gestão democrática no ensino público (BRASIL, 1998).

Do discurso governamental para a sua efetivação, no entanto, há uma distância, que não se concretizou, da maneira esperada. Por não assumir as necessidades surgidas, lembram Janial e Di Giorgi (2010, p.7), “o governo agiu de acordo com as políticas neoliberais, desobrigando-se das responsabilidades de efetivação das políticas educacionais e passando a responsabilidade a outras esferas", tais como a iniciativa privada e organizações não governamentais.

A imaturidade do Brasil com a forma de atuação política aberta e participativa é, na visão de Gadotti (2001, 2014), uma das razões que acabam por justificar o comprometimento de uma gestão democrática promotora de diálogo. A experiência com a democracia ainda é incipiente, o sistema educacional ainda é verticalizado e, como reflexo, o envolvimento e a participação popular nas decisões ainda são dificultadas.

Na proposta do Conselho Nacional do Ministério Público (CNMP), mais especificamente, no documento Diálogos e Mediação de Conflitos nas Escolas: Guia Prático para Educadores, objeto de análise desta pesquisa, o diálogo é referência, como uma prática constante que deve ser praticada diante de diversos prismas, dos quais, destaca-se a vertente da interação entre sujeitos, como elemento de aglutinação (BRASIL, 2014). O documento ainda se volta para o diálogo em outras situações e conceituações, sempre posicionando a escola como instituição ativa no processo de capacitar o estudante para o diálogo, ora ensinando-o a "importância do diálogo e da paz, visando capacitá-los para um conjunto de habilidades necessárias para o desenvolvimento de uma personalidade equilibrada", ora como uma "cultura para a não violência" (BRASIL, 2014, p. 12).

A violência, no documento, se revela sob vários aspectos: econômica, física, verbal, institucional, doméstica, moral, patrimonial, psicológica, sexual, negligência, de poder, profissional, entre outras. Essa materialização da violência, para Oliveira e Martins (2007), não se funda como uma invenção exclusiva da sociedade atual, porém, acaba por se configurar como um cenário que vem se fortalecendo, de forma constante, em nossas vidas.

Tendo o documento Diálogos e Mediação de Conflitos nas Escolas: Guia Prático para Educadores como referência, assumiram-se as seguintes problemáticas de pesquisa: $\mathrm{O}$ diálogo anunciado contribui para a gestão democrática? Em caso positivo, como se dá essa contribuição e qual o seu alcance? E, qual a importância concedida ao diálogo, na construção da noção de pertencimento dos sujeitos no processo de gestão escolar?

Diante de tais questionamentos, no mesmo viés, a pesquisa assumiu como objetivo central, analisar a concepção de gestão democrática e de diálogo presentes na proposta do Conselho Nacional 


\section{Dialogia}

do Ministério Público para a mediação de conflitos nas escolas brasileiras.

\section{Disposição da roda de conversa: aspectos metodológicos}

Esta pesquisa é de natureza qualitativa, sendo adota a análise documental como procedimento metodológico. A opção por essa modalidade, parte do pressuposto de que os documentos podem disponibilizar informações que permitam compreender os fatos e as suas relações, sem se prender em métricas quantitativas (GODOY, 1995).

Como explicam Souza, Kantorski e Luis (2011), também admitem avaliar o período histórico e social das ações, além de possibilitar que os acontecimentos e os momentos que os antecederam sejam resgatados e reconstruídos, permitindo que se conheçam manifestações de aspectos da vida social de determinados grupos. Cellard (2008) assinala como aspecto relevante da análise documental, o fato de que a apreciação de documentos registrados também permite observar o amadurecimento ou evolução de indivíduos, grupos, bem como apreciar conceitos, verificar conhecimentos, detectar comportamentos, mentalidades, práticas, entre outros.

Dada à abrangência do documento Diálogos e Mediação de Conflitos nas Escolas: Guia Prático para Educadores, optou-se para uma reflexão em torno da gestão democrática e quais os impactos que esse modelo de gestão proporciona no Projeto Político Pedagógico. Em seguida, voltou-se para uma apreciação em torno do fortalecimento das relações interpessoais, ação considerada como forma de combate às manifestações de violência, que no Guia aparece em forma de sugestões atividades para que os docentes trabalhem com seus estudantes e comunidade escolar.

Para tanto, a apreciação do Guia ocorrerá por meio de duas unidades analíticas. A primeira será “A gestão democrática e seus impactos no Projeto Político Pedagógico: uma análise da perspectiva do Guia". A segunda intitula-se "O Guia e o fortalecimento das relações interpessoais como forma de combate às manifestações violentas e conflitivas: a necessidade de expansão do diálogo".

\section{Análise e discussão dos dados}

\subsection{A gestão democrática e seus impactos no Projeto Político Pedagógico: uma análise da perspectiva do Guia}

A configuração do documento e a chamada da escola para a proposta de ações em torno de um grave problema social, que tem fundamentos na ausência do diálogo em suas várias instâncias, parte do 


\section{Dialogia}

levantamento de dados relacionados à violência dentro e fora das escolas, subsídios que, se mostravam como "bastante preocupantes e evidenciam que o respeito, fundamento da desejada convivência saudável, na prática vem sendo submetido à progressiva deterioração” (BRASIL, 2014, p. 3).

Reitera-se, o Guia foi escrito a partir das vivências do promotor de Justiça no Estado de São Paulo, Antonio Carlos Ozorio Nunes. O CNMP investiu no Guia sobre a justificativa de que, “[...] essa experiência do autor já foi exitosamente dividida com quase dez mil educadores da rede estadual de ensino paulista, por meio de cursos presenciais e à distância, e é agora compartilhada em formato livro, de fácil transporte, manuseio e consulta" (BRASIL, 2014, p. 3).

Infere-se que o diálogo presente segue roteiro pronto. $\mathrm{O}$ documento não explicita, neste cenário, que houve uma participação coletiva nas discussões e proposições que são desencadeadas. Apesar do diálogo se fazer presente nas propostas de debates e nas atividades sugeridas pelo Guia, reitera-se que não se trata do diálogo propriamente democrático, fato que compromete a concepção de escola democrática. Apple e Beane (1997, p. 17), nesse sentido, apontam que para que as escolas se caracterizem como "escolas democráticas" são fundamentais que se apresentem algumas condições. Destacam- se, por exemplo, o livre fluxo das ideias, a fé na capacidade individual de cada participante e a reflexão e a análise crítica para avaliação de ideias, problemas e condições políticas.

No Guia, a participação coletiva, as sugestões de ideias e a prática de diálogos surgem com muita frequência nas atividades sugeridas para as ações práticas propostas aos professores para que, posteriormente, trabalhem com os seus estudantes. Porém, quando os professores e a escola recebem o documento pronto, perdem, automaticamente, suas capacidades para a autonomia, outro princípio básico para a efetivação da gestão democrática.

Na escola, a ideia de autonomia, como destaca Krawczyk, (1999, p. 119) se constrói como sinônimo de auto-organização. Para que a autonomia e a gestão democrática possam então, de fato, existirem, aponta a autora, "nesse caso, convoca- se a participação coletiva dos diferentes atores educativos nos processos de planejamento e na avaliação do funcionamento da escola". A própria autora se encarrega de lembrar que "as escolas não são uma continuação natural da ordem normativa na prática, mas realidades complexas organizadas em torno dessa ordem” (KRAWCZYK, 1999, p.119).

Ao propor diálogos, ao apresentar as propostas de atividades, ao sugerir quais os caminhos que devem ser adotados, há uma prática que corre no sentido adverso da aplicação da própria democracia (PARO, 2001; GADOTTI, 2014). Quanto à qualidade das participações, há dados significativos no Guia que carecem de uma atenção detalhada:

[...] Nesta publicação, constam ainda depoimentos de educadores que, estimulados pelas informações nele trazidas, protagonizaram, com o seu alunado, transformações extraordinárias no ambiente escolar, concretizando o valor respeito que tanto se busca. Espera-se que cada 


\section{Dialogia}

educador, com a sua rica vivência em sala de aula, numa escola de capital, cidade do interior ou zona rural, encontre nas linhas que seguem mais uma razão para perseverar ensinando e formando cidadãos (BRASIL, 2014, p. 3).

Do recorte acima, salta um parêntese para a atenção e o cuidado que devem estar sempre presentes quando, no ofício de educar, o professor deve se apropriar de um produto que não lhe pertence ou não pertence à realidade local que, na visão de Costa, Fernandes Neto e Souza (2009) pode levar à alienação do profissional no exercício de suas funções. Diferentemente daquilo que recebe pronto, "o conhecimento que o professor organiza e elabora com fins de ensino ninguém pode lhe roubar" (COSTA; FERNANDES NETO; SOUZA, 2009, p. 76).

Quando o que se está em discussão é a qualidade das relações e dos trabalhos no contexto escolar, é preciso lembrar que para a consolidação de uma gestão democrática, de forma bastante efetiva, é necessário um Projeto Político Pedagógico. Trata-se de um instrumento que encontra respaldo na LDB (BRASIL, 1996), que, especificamente nos artigos 13 e 14, aponta que a elaboração da proposta pedagógica deve contar com a participação dos profissionais da educação.

[...] ao se constituir em processo democrático de decisões, preocupa-se em instaurar uma forma de organização do trabalho pedagógico que supere os conflitos, buscando eliminar as relações competitivas, corporativas e autoritárias, rompendo com a rotina do mando impessoal e racionalizado da burocracia que permeia as relações no interior da escola, diminuindo os efeitos fragmentários da divisão do trabalho que reforça as diferenças e hierarquiza os poderes de decisão (VEIGA, 2002, p. 3).

No Guia, o Projeto Político Pedagógico se apresenta de forma modesta. Além de constar uma breve conceituação sobre o que é projeto, porque é político e porque é pedagógico, há uma menção pouco profunda a não ser para o fato de que se trata de um projeto que serve como "referência e um norte para os agentes envolvidos na ação educativa da escola e não deve ser feito apenas para cumprir uma formalidade e ficar guardado na gaveta" (BRASIL, 2014, p. 64).

Em outros momentos o Guia faz referência ao Projeto Político Pedagógico, ainda sem entrar na profundidade que o tema merece. No item que traz observações sobre a gestão da escola democrática, por exemplo, a construção coletiva do Projeto Político Pedagógico surge como representação da democracia na escola e como exemplo de participação nas ações da escola. Dentre as formas de participação na construção do Projeto Político Pedagógico, o Guia rapidamente faz referência às assembleias escolares, práticas que possibilitam que a comunidade escolar possa discutir temáticas e participar das ações relativas à vida funcional e administrativa da escola (BRASIL, 2014).

Nesse contexto, a proposta do CNMP suscita ponderações. Ao propor ações para o combate à violência no contexto escolar, adota um posicionamento de rejeição e instiga reflexões em torno da busca de ações para que removam do contexto escolar a violência que constrange a sua comunidade (BRASIL, 2014). Por outro lado, adota o discurso em suas linhas de que a escola deve estar preparada 


\section{Dialogia}

para uma série de funções que, em princípio, deveriam ser atribuições compartilhadas com outros segmentos políticos, legais, sociais e familiares, dentre outros.

No capítulo que trata, por exemplo, da busca do trabalho em parceria e em rede para uma escola cidadã, os autores do Guia observam que a escola precisa ter uma "boa gestão democrática", também deve "manejar bem as ferramentas para solucionar positivamente os conflitos". O documento reconhece, na sequência que, muitas vezes, o desafio da escola é ainda maior, quando se depara, por exemplo, "com jovens que estão com transtornos psiquiátricos, com dependência química, com distúrbios psíquicos, com agressividades crônicas, entre outros problemas mais complexos e de difícil solução" (BRASIL, 2014, p. 68).

Para incorporar ainda mais a lista de atribuições, o documento sinaliza que a escola também pode se encarregar de realizar diagnósticos para identificar alunos com problemas, realizar entrevistas e aplicar questionários e pesquisas que visem ao registro de histórico e acompanhamento individual dos alunos que apresentam problemas, uma vez que os autores entendem que, "assim, a escola estará cuidando com mais atenção de quem necessita de mais cuidado" (BRASIL, 2014, p. 68).

Quando Barata-Moura (2005) aborda o conceito de liberdade, no sentido positivo do termo, entende como sinônimo de estar livre para, isto é, defrontar o mundo como sede de um poder de auto direção. "A liberdade, fundamentalmente, é a auto fundação enraizada de um destino, de uma destinação que um sujeito (de figura individual ou não) a si próprio se dá” (BARATA-MOURA, 2005, p. 72). Diante dessas reflexões, ao dilatar o rol de imputações à escola, por um lado estreita-se o conceito de liberdade da escola, por meio da descentralização, e amplia-se, por outro, o grau de responsabilização que também é conferido à própria escola. A essa instituição é canalizada, quase que obrigatoriamente, uma série de funções, compromissos e responsabilidades que deveriam estar sendo desenvolvidas e ou executadas por outros órgãos e instituições, principalmente pelo Estado.

\subsection{O Guia e o fortalecimento das relações interpessoais como forma de combate às manifestações violentas e conflitivas: a necessidade de expansão do diálogo}

A proposta da elaboração do material intitulado Diálogos e Mediação de Conflitos nas Escolas: Guia Prático para Educadores, ganhou forma a partir da análise de dados relacionados à violência dentro e fora das escolas. Logo na apresentação do documento, justifica-se a preocupação com o aumento da violência envolvendo a comunidade escolar (BRASIL, 2014).

$\mathrm{Na}$ proposta, aborda-se o diálogo como uma alternativa para a abertura de caminhos que conduzam a sociedade, através da escola, em busca de soluções que possam contribuir com a amenização da violência que atinge a própria comunidade. E qual o motivo do CNMP propor essas 


\section{Dialogia}

ações de trabalho dentro da escola? O próprio órgão, ainda na apresentação do documento tenta dar a sua resposta, ao expor que estaria contribuindo diretamente com as escolas e com a sociedade "num enfoque substancialmente preventivo de ações, sobretudo por ser a escola um local privilegiado para a propagação de valores" (BRASIL, 2014, p. 4). O órgão, mais à frente, em suas justificativas, com as ações propostas em seu Guia, acredita estar dando a sua contribuição também para a criação e uma cultura de prevenção à violência.

No entanto, o documento do CNMP não faz referência e não propõe reflexões acerca do papel social da escola. Ao pensar sobre quais são as principais atribuições da escola, Saviani (2012), por exemplo, alerta para o fato de que para chegar às respostas é preciso levar em consideração o cenário de que, por ser a escola determinada socialmente, encontra- se inserida numa sociedade fundada na produção capitalista, dividida em classes, cada qual defendendo interesses adversos. Soma-se a isso o fato de que a escola se constituir também como um instrumento de reprodução das relações na sociedade capitalista, além de reproduzir a dominação e a exploração.

Desconsiderando essas ponderações, o documento se encarrega de apontar que os conflitos também são ricas oportunidades para aprendizagem. No segundo capítulo, por exemplo, os autores sugerem uma atividade com alunos intitulada termômetro da violência. Essa ação se configura por meio de um questionário que deve ser preenchido pelos estudantes e também pela equipe escolar, cujos objetivos são identificar quais as formas de violência viventes na escola. Sobre essa prática, alertam os autores, no entanto, que o questionário precisa ser aplicado em uma ou mais classes. Posteriormente, os resultados deverão ser tabulados, devendo ficar à disposição para que a comunidade escolar avalie e elabore programas preventivos. Outra orientação é que o questionário deve ser repetido de tempos em tempos, sob o pretexto de se verificar se houve melhorias na organização educativa (BRASIL, 2014).

Mais à frente, no terceiro capítulo, o Guia, ao sugerir práticas restaurativas, sugere a atividade "violência gerando notícias", cujo objetivo é promover ideias e discussão de soluções para as diversas formas violência, apresentadas nos artigos trazidos pelos alunos. A justificativa dos autores para essa ação é de que: "busca-se vencer barreiras que nos impedem de enxergar soluções para os problemas apresentados e criar um clima de otimismo no grupo, mostrando que para os problemas podem existir soluções” (BRASIL, 2014, p. 24).

Após essas verificações, a abordagem direta à violência, no Guia, vai aparecer somente no capítulo 10, onde é abordado o tema do adolescente e o ato infracional, especificamente na sugestão de uma atividade prática intitulada o enfrentamento da violência nas escolas. Essa sugestão de atividade, no entanto, se resume à indicação de uma leitura complementar, especificamente da Proposta Conte até 10 nas Escolas. 


\section{Dialogia}

Em outros momentos em que o termo violência se mostra presente, sempre está vinculado com a escola, como sendo a responsável pelos cuidados. Assim, trabalhar as questões de violência na escola é papel do professor, do diretor, da comunidade interna e externa, do Projeto Político Pedagógico e dos grêmios estudantis, por exemplo. Toda essa visão dos autores é amparada no suporte de que, “uma escola democrática deve se preocupar em formar jovens ativos, responsáveis, protagonistas e capazes de solucionar as suas demandas e problemas por meio do diálogo, da negociação e da cooperação" (BRASIL, 2014, p. 66).

A partir do momento em que sugere reflexão e ação para o combate à violência dentro da escola, a proposta do CNMP passa a ser válida. Há a propensão para a valorização do diálogo como instrumento para o fortalecimento das relações interpessoais, modelo de ação que, de acordo com os autores do Guia, se caracterizaria também como forma de combate às manifestações violentas e conflitivas. No entanto, há outros elementos fundamentais para a garantia de ações mais efetivas que deveriam estar presentes de forma mais contundente. Uma dessas possibilidades é pensar que a escola não está sozinha nessa jornada. O Estado, por exemplo, tem papel central nesse processo, sobretudo porque a desigualdade social e econômica é fruto das relações capitalistas, essas que produzem inúmeras situações de violências (FRANCISCO; LIBÓRIO, 2015).

Francisco e Libório (2015) sugerem que nas análises para a compreensão do fenômeno da violência escolar sejam consideradas as influências de outros importantes aspectos, como os históricoculturais. É preciso ponderar que as demonstrações de violência precisam ser entendidas como manifestações que o homem constrói nas suas interações sociais.

Diálogo, gestão democrática e violência são entes conexos no contexto da Educação e, portanto, carecem de ações também aproximadas, sem as quais, as possibilidades de acertos não se concretizam. Somente sugerir atividades e adaptá- las a contextos específicos não se traduz em promessa de eficácia, uma vez que há uma complexidade muito maior na composição humana dos sistemas escolares.

Outra ponderação importante que deve ser precedida é que as ações e atividades que o Guia propõe não se configuram como práticas sistematizadas que devem ser promovidas num espaço temporal ilimitado, permanente. Soam, pelo contrário, como programas que visam a uma emergencialidade, postas para o atendimento de necessidades específicas e pontuais, dentro do contexto da violência, cujo cenário é muito maior e envolve muitas outras facetas, sobretudo no que diz respeito às relações entre Estado e sociedade. Partindo do princípio de que a educação é também uma prática social é possível compreender que na dimensão do tema, a violência na escola precisa ser tratada levando em consideração que a realidade impõe outros desafios, uma vez que: 


\section{Dialogia}

Há a ilusão de que um simples programa de intervenção ou a elaboração de uma política pública em âmbito nacional seriam capazes de erradicá-lo. Como consequência, se estaria por ignorar várias dimensões que exercem influência em sua configuração, tais como, os aspectos sociais, políticos, econômicos e culturais, como se a problemática fosse decorrente, apenas, das relações isoladas entre um ou vários sujeitos na realidade, desconsiderando-se a determinação da totalidade social nesse processo. Esses são desafios que precisam ser repensados, até mesmo porque se for estabelecida uma relação com os programas de intervenção [...], percebe-se que, na maioria das vezes, os mesmos advêm de relações verticais que não contemplam a heterogeneidade dos sujeitos sociais (FRANCISCO; LIBÓRIO, 2015, p. 18).

Ao pensar em ações e soluções ligadas às resoluções de conflitos nas escolas, Francisco e Libório (2015, p. 22) ressaltam a necessidade de que as abordagens se processem em camadas mais profundas, abordando "questões mais estruturais ligadas à produção do fenômeno". Esse argumento sinaliza que, ao pensar na base do problema, envolvidos diretamente nessa reflexão, os estudantes e a comunidade escolar podem compreender "que as suas posturas refletem a realidade, a partir de determinadas condições objetivas de vida".

\section{Estendendo a conversa: considerações finais}

Ao buscar os vínculos entre a gestão democrática e o diálogo, a partir das análises em torno da proposta do Ministério Público para a mediação dos conflitos nas escolas, algumas contradições foram identificadas no Guia, o diálogo proposto não coaduna para a efetivação de uma gestão escolar democrática. Quando os professores e a escola recebem um documento pronto, a fim de se atuar diante das situações promotoras de violência, perdem, automaticamente, suas capacidades para a autonomia, princípio basilar nessa perspectiva.

Ao propor ações para o combate à violência no contexto escolar, fica explícito o discurso de descentralização defendido pelo CNMP, segundo o qual a escola deve estar preparada para uma série de funções que, em princípio, deveriam ser atribuições compartilhadas com outros segmentos políticos, legais, sociais e familiares, bem como do próprio Estado. Na lógica apresentada corre-se o risco de criar um excesso de responsabilização dos sujeitos envolvidos nas comunidades escolares.

Além disso, as ações de combate aos conflitos e às violências escolares devem ser pensadas coletivamente, de tal forma que os membros de uma comunidade educativa consigam correlacioná-las com os determinantes sociais e culturais. Por meio de intencionalidades mais amplas poderão ser propostas reflexões e vivências de caráter permanente, as quais deverão assumir a necessidade premente de transformação das relações sociais.

${ }^{1}$ Esta pesquisa é um recorte de dissertação de mestrado defendida na área de Educação. 


\section{Dialogia}

GOMES, Alessandro; FRANCISCO, Marcos Vinicius. Análise da proposta do Ministério Público para a mediação de conflitos nas escolas: concepções

2 Para Chauí (2007) o "discurso competente" é aquele que pode ser proferido, ouvido e aceito como verdadeiro ou autorizado, simplesmente, porque aquele que o profere perdeu os laços com o lugar e o tempo de sua origem. Além disso, ao ser empregado como "competente" por quem o dispara, automaticamente subjuga como "incompetente" quem acata ao discurso proferido, numa clara demonstração de dominação de classes e interesses.

\section{Referências}

APPLE, Michel; BEANE, James. Escolas democráticas. São Paulo: Cortez, 1997.

ARAÚJO, Ulisses Ferreira de. O déficit cognitivo e a realidade brasileira. In: AQUINO, Julio Groppa. (Org.). Diferenças e preconceito na escola: alternativas teóricas e práticas. 4. ed. São Paulo: Summus Editorial, 2000. p. 31-47.

BARATA-MOURA, José. Para uma ontologia da educação. 2005. Disponível em: http://www.cnedu.pt/content/antigo/files/pub/BasesEducacao/6-AutonomiaLiberdade Responsabilidade.htm. Acesso em: 12 nov. 2015.

BRASIL. Constituição (1988). Constituição da República Federativa do Brasil. Brasília: Senado Federal, 1988.

BRASIL. Congresso Nacional. Lei no 9.394 de 20 de dezembro de 1996. Estabelece as diretrizes e bases da educação nacional. Diário Oficial da União, Brasília, DF, 23 dez. 1996. Disponível em: http://www.planalto.gov.br/Ccivil 03/leis/L9394.htm Acesso em: 03 nov. 2017.

BRASIL. Conselho Nacional do Ministério Público. Diálogo e Mediação de Conflitos nas Escolas. Guia prático para Educadores. Brasília: Conselho Nacional do Ministério Público, 2014.

CELLARD, André. A análise documental. In: POUPART, Jean; DESLAURIERS, Jean-Pierre; GROULX, Lionel-H.; LAPERRIÈRE, Anne; MAYER, Robert; PIRES, Álvaro. A pesquisa qualitativa: enfoques epistemológicos e metodológicos. Petrópolis, Vozes, 2008. p. 295-316.

CHAUÍ, Marilena. Cultura e democracia: o discurso competente e outras falas. 12. ed. -São Paulo: Cortez, 2007.

COSTA, Áurea; FERNANDES NETO, Edgard; SOUZA, Gilberto. A proletarização do professor. neoliberalismo na educação. São Paulo: Instituto José Luís e Rosa Sundermann, 2009.

CUNHA, Luiz Antônio. O legado da ditadura para a educação brasileira. Educação \& Sociedade, Campinas, v. 35, n. 127, 357-377, abr./jun. 2014.

FRANCISCO, Marcos Vinicius; LIBÓRIO, Renata Maria Coimbra. Notas sobre alguns desdobramentos necessários nos programas de combate ao bullying escolar: uma análise históricocultural. Interacções, Lisboa, n, 38, p. 07-27, 2015.

FREIRE, Paulo. Política e educaşão: ensaios. 5. ed. São Paulo: Cortez, 2001.

FREIRE, Paulo. Pedagogia do oprimido. 46. ed. Rio de Janeiro: Paz e Terra, 2005.

GADOTTI, Moacir. Pedagogia da práxis. São Paulo: Cortez, 2001. 


\section{Dialogia}

GADOTTI, Moacir. Gestão democrática com participação popular no planejamento e na organização da educaşão nacional. Brasília: Ministério da Educação, 2014.

Disponível em: http://conae2014.mec.gov.br/images/pdf/artigogadotti final.pdf. Acesso em: 26 nov. 2015.

GERARD Glenna; TEURFS, Linda. Diálogo e transformação organizacional, Tradução: Júlio Tôrres. 2010. Disponível em: http://www.teoriadacomplexidade.com.br/textos/dialogo/ Dialogo-e-TransformacaoOrganizacional.pdf. Acesso em: 10 fev. 2016.

GODOY, Arilda Schmidt. Introdução à pesquisa qualitativa e suas possibilidades. Revista de Administração de Empresas da EAESP/FGV, São Paulo, v. 35, n. 2, p. 57-63, mar/abr. 1995.

JANIAL, Márcia Aparecida Pinheiro; DI GIORGI, Cristiano Amaral Garboggini. A redemocratização do ensino - avanços, retrocessos e qualidade da educação popular. Saber acadêmico, Presidente Prudente, n. 10, p. 3-14, dez. 2010.

KRAWCZYK, Nora. A gestão escolar: um campo minado: análise das propostas de 11 municípios brasileiros. Educação \& Sociedade, Campinas, v. 20, n. 67, p.112-149, 1999.

OLIVEIRA, Érika Cecília Soares; MARTINS, Sueli Terezinha Ferreira. Violência, sociedade e escola: da recusa do diálogo à falência da palavra. Psicologia \& Sociedade, Belo Horizonte, v. 19, n. 1, p. 90-98, jan./abr. 2007.

PARO. Vitor Henrique. Escritos sobre educação. São Paulo: Xamã, 2001.

PARO. Vitor Henrique. Gestão democrática da escola pública. São Paulo: Ática, 2004. PERSONAL

SAVIANI, Dermeval. Escola e democracia. 42. ed. São Paulo: Cortez Autores Associados, 2012.

SOUZA, Jacqueline; KANTORSKI, Luciane Prado; LUIS, Margarita Antonia Villar. Análise documental e observação participante na pesquisa em saúde mental. Revista Baiana de Enfermagem, Salvador, v. 25, n. 2, p. 221-228, maio/ago. 2011. Disponível em: http://www.portalseer.ufba.br/index.php/enfermagem/article/viewArticle/5252. Acesso em: $11 \mathrm{de}$ nov 2015.

VEIGA, Ilma Alencastro Passos. Projeto político-pedagógico da escola uma construção possível. 14. ed., Campinas: Papirus, 2002.

Recebido em: 30 abr. 2019 / Aprovado em: 25 jun. 2019

\section{$\underline{\text { Cite como }}$}

GOMES, Alessandro; FRANCISCO, Marcos Vinicius. Análise da proposta do Ministério Público para a mediação de conflitos nas escolas: concepções de gestão democrática e diálogo. Dialogia, São Paulo, n. 32, p. 108-119, maio/ago. 2019. Disponível em: https://doi.org/10.5585/Dialogia.n32.13757. 